
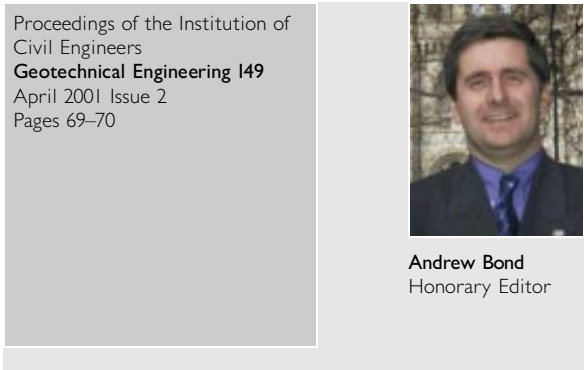

Honorary Edito

\title{
Editorial
}

\section{Andrew Bond}

\section{BRIEFINGS}

In this issue we have what I hope will become a regular feature of Geotechnical Engineering: briefing notes on topics of general interest to geotechnical engineers.

I am particularly pleased to kick off this section of the journal with a piece written by Professor Ralph Peck entitled 'The observational method can be simple', using case notes from his work with Terzaghi in the 1930s/40s. This piece is the first of a series we plan to run on the observational method in the next few issues.

Our second briefing, by Preene and Brassington, discusses forthcoming changes to the legislation covering ground dewatering works and warns that failure to comply with the new regulations may result in prosecution.

\section{PAPERS}

Groundwater conditions had a great bearing on the geotechnical design of the A331 Winchester to Guildford road in the vicinity of the River Blackwater (see figure). The paper by Stephen describes the site investigation undertaken, the ground and groundwater conditions encountered, and the construction of earthworks and piled foundations.

Geographical Information Systems (GIS) look set to revolutionise the way geotechnical engineers interrogate, analyse, and present spacially-related information. By way of four case histories, Hellawell et al. demonstrate the potential for GIS to become a powerful but routine office tool. They argue that geotechnical engineers are ideally placed to lead the development of this technology within civil engineering projects.

Computer modelling is providing greatly increased power to generate and transfer information, but safeguards are needed to ensure the competent use of this generated material. Drawing on the work of an Institution of Structural Engineers Task Group, Bond and MacLeod present a strategy for computer modelling in geotechnical design that clearly differentiates between engineering, conceptual and computational models.

Ivanovic et al. use numerical modelling to simulate the dynamic response of single tendon ground anchorage systems.
One outcome of this research has been the development of a new method for non-destructive testing of anchorages.

The efficient disposal of tailings from gold mining operations in Western Australia relies on successive layers of hydraulically discharged clay drying sufficiently before the next layer is placed on top. Newson and Fahey describe the use of a specially modified hovercraft—fitted with shear vane, piston, cone, and other equipment-to investigate the properties of these tailings following deposition.

Finally, we have discussion of the paper by Blanchford and Anderson on 'Wetting collapse in opencast coalmine backfill' that appeared in the July 2000 issue.

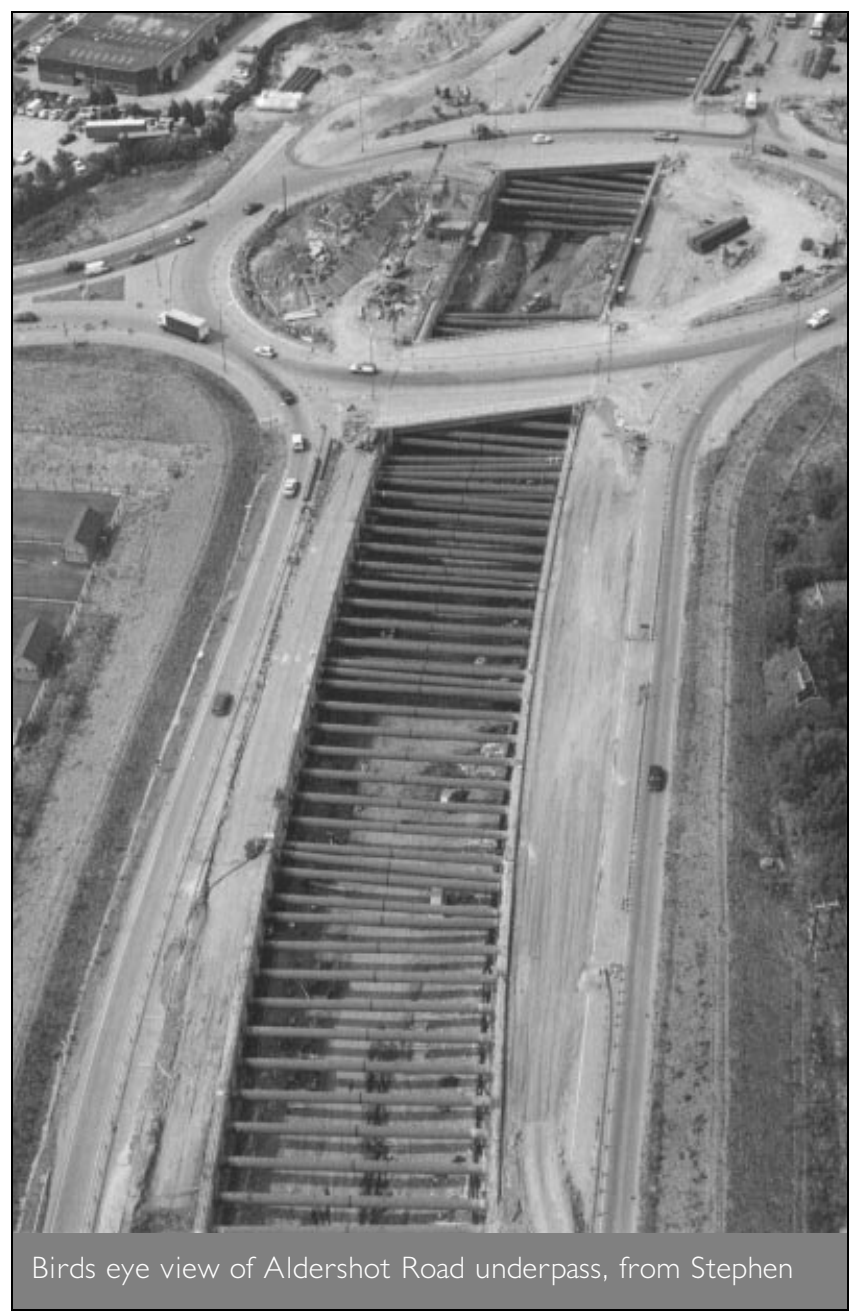




\section{NEXT ISSUE}

The July issue of Geotechnical Engineering will feature the second in our series of papers on the observational method; a paper on widening and deepening adjacent large shafts in rock; and the first installment of a history of the early days of soil mechanics in Great Britain. Don’t miss it!

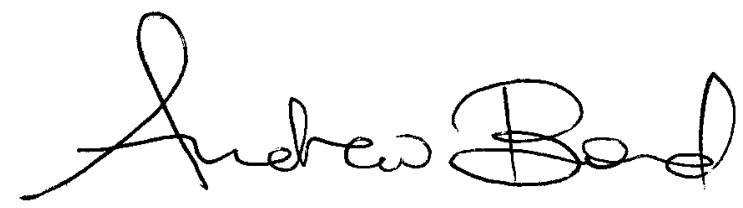

